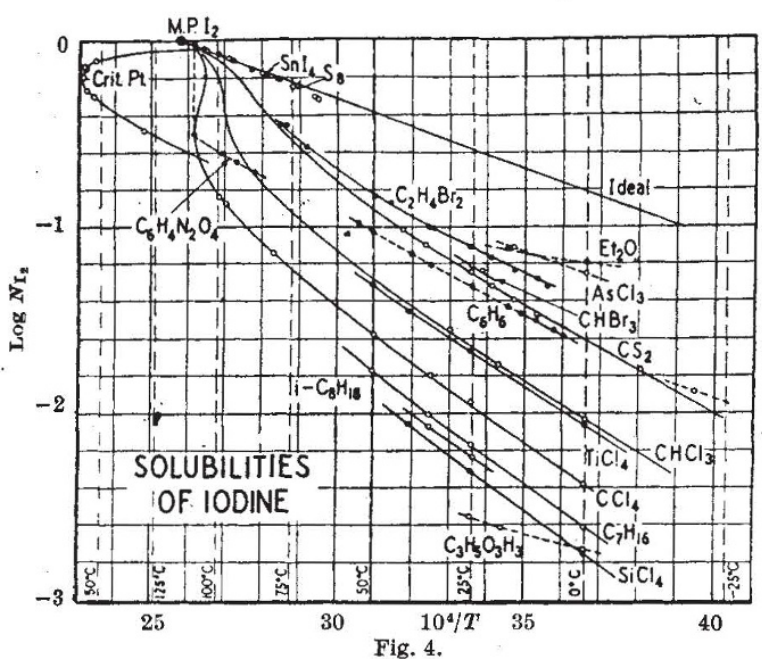

means that Raoult's law will hold for mixtures of the same species of molecule, that is, for molecules of equal size, shape and field of force. We can vary this condition by mixing different species and comparing the partial pressures. An interesting case is a mixture of molecules of equal field-strength, but of different size. Here the conceptions of the osmotic school, expressing concentrations in moles per litre, break down. According to these conceptions, we should expect, for example, ethane under one atmosphere to dissolve to the same extent in a given volume of any higher paraffin. On the other hand, the mole fraction of a given amount of ethane in dodecane would be twice that in the same volume of hexane. To achieve the same solubility the pressure of ethane over dodecane would have to be doubled. It is the latter alternative that is supported by the experiment. Normal paraffins of different length such as butane and heptane obey Raoult's law. It simply means that only the space between the molecules of the solvent is at the disposal of the second component, and not the total volume.

The properties of solutions offer almost unlimited scope for obtaining information on the problems of the liquid state. The same considerations as applied to the evaluation of the potential between a pair of identical molecules can be employed in evaluating potentials between molecules of different kind. If we have spherical molecules of equal size, but different molecular fields, the $W$-function is the same as in the pure liquid and can be made the base of calculations. Of the great number of examples given by Prof. Hildebrand, the set dealing with a comparison of different solvents for iodine is perhaps the most instructive one. The solubilities for this substance are given in Fig. 4. Most of the curves belong to one family; they represent 'regular solutions' for which computation on the lines indicated above is possible. They all show the violet colour of iodine vapour, which indicates that the iodine molecules are simply dissolved and have not taken part in chemical changes. The solutions corresponding to the non-regular curves, on the other hand, have different colours and make one suspect that chemical changes have occurred. Prof. Hildebrand directed special attention to the loop intersecting the curve for carbon tetrachloride. Calculation shows that the curve running through the points for the solubility of solid iodine must exhibit an S-shape, which means that there are two composi- tions in equilibrium at the same temperature. Experiments which had to overcome the difficulty that iodine solutions of such high concentration are quite opaque gave the completeliquid-liquid solubility curve in close approximation with the calculated values.

Results such as this show how far theoretical interpretation of the liquid state can provide an explanation of the observed phenomena, and can even be used in the prediction of conditions of considerable complexity. In his conclusion, Prof. Hildebrand left no doubt, however, that while there are remarkable achievements already at hand, the liquid state still abounds in unexplained phenomena which await elucidation when scientific men can return to its problems after the War. K. Mendelssonn.

\section{NUTRITION AND A MATTER OF TASTE}

\section{BY DR. MAGNUS PYKE}

$\mathrm{D}$ URING the past twenty-five or thirty years the science of nutrition has made very great strides. These advances have been due almost entirely to the application of precise, objective, chemical methods, and have been paralleled by similar advances in other branches of biology. Those who study endocrine secretions can determine, according to his endocrine balance, how the character of a man will be in. fluenced. Similarly, the nutritionist can say from an analysis of the foodstuffs of which a man makes up his diet whether or not, and in what way, his body will be influenced for good or evil. By these means it is now possible to decide, to a greater or less degree of precision, the physiological needs of such divers individuals as pregnant women, adolescent children or coal-miners for calories, protein, fat, four or five mineral substances and six or seven vitamins. In making these advances in knowledge, the subjective feelings of the individuals concerned have not only been neglected; they have specifically been excluded. This has led to several curious conclusions, two at least of which may be cited.

There is, for example, no scientific evidence to suggest that violent muscular work has any influence whatever on the physiological demands of an individual for animal protein; yet there is a widespread popular belief that meat is essential for the efficient prosecution of manual labour. Similarly, so far as the classical nutritionist is aware, onions, garlic and pickles are of negligible nutritional value. Nevertheless, so pressing is the popular demand for such condiments that Britain, faced with extreme pressure on her land for food and aerodromes, is compelled to devote a substantial acreage to their culture.

Now, into the traditional, generation-old field of respectable nutrition comes Prof. Curt Richter, of the Johns Hopkins University School of Medicine*, with a summary of a number of inconvenient papers which have been appearing in the physiological literature during the last ten years, and the implications of which have largely been ignored by nutritionists.

Prof. Richter begins quietly. If rats are kept in a cage on a salt-free diet and given the opportunity of drinking a 3 per cent salt solution out of a graduated tube they will, on the average, drink enough of the

" "Total Self-regulatory Functions in Animals and Human Beings." Curt P. Richter. The Harvey Lectures Series, 38, 63 (1942-43). 
solution to provide for their nutritional needs. If the animals are then adrenalectomized, the consumption of the solution of sodium chloride increases enormously even if other solutions are made available. If, on the other hand, the calcium metabolism of rats is disturbed by parathyroidectomy, their appetite for solutions of calcium salts increases and also their desire for salts of ehemically related metals such as strontium and magnesium, but not for any other substances.

The next stage of the work was clearly to divide the animals' diet into all its constituent nutrients, and this Prof. Richter did. The rats were placed in eages equipped with several food cups containing, separately, weighed amounts of purified carbohydrate, protein, fat and such materials as dried yeast. Furthermore, they were confronted with from eight to twenty graduated tubes containing measured amounts of solutions of sodium chloride, potassium chloride, calcium lactate, sodium phosphate, magnesium chloride, aneurin, riboflavin, nicotinamide, calcium pantothenate, choline chloride, pyridoxin hydrochloride, biotin, cod-liver oil and any other of the substances it was desired to test.

Some of the results were of surprising interest. For example, when presented with this plethora of choice among substances never normally encountered pure in Nature, and many of which are devoid of any definite taste or smell, not only did the rats choose for themselves a perfect diet, according to the most up-to-date nutritional knowledge, but also they made on their self-chosen diet more economical growth than on a stock diet of non-purified foods. When the rats were depancreatized, they spontaneously avoided carbohydrate and maintained their calories with fat. When the bottle containing aneurin, which is specifically concermed with the intermediary metabolism of non-fat calories, was taken away, the rats reduced their consumption of non-fat calories and ate more fat. When given aneurin but deprived of riboflavin, nicotinamide and pyridoxin, the animals ate more carbohydrate, some fat but almost no protein, thus suggesting that one or other of these vitamins is specifically concerned with intermediary protein metabolism.

Further interesting results were obtained by following the diet which was spontaneously chosen by female rats during the course of pregnancy and lactation. As might, perhaps, have been expected, the calcium consumption rose only slightly during pregnancy but increased very markedly during lactation. An unexpected finding was, however, that the sodium chloride intake increased during pregnancy, and increased again even more substantially during lactation.

What is the application of this line of approach to problems of human diets? Man has survived for some few thousand years on a self-chosen diet so that, presumably, even without the benefits of academic qualifications in nutrition, he must apparently possess certain powers of discriminating what is good for him. But one has only to look at the physique of the population of a London underground station during an air raid, or notice the enormous incidence of defective teeth among the bulk of even the younger members of the British industrial population, to realize that laisser-faire in human nutrition is not enough. Prof. Richter's rats can practise selfselection in their diets when each nutrient is separated from the other. Sir Jack Drummond, on June 27 from the chair of the Nutrition Panel meeting of the
Food Group, Society of Chemical Industry, at Burl. ington House, commented that workmen, who could be demonstrated clinically and biochemically to te deficient in vitamin $\mathrm{C}$, would yet refuse a salad from the best intentioned British restaurateur. The explanation may be that if these men had the freedom of choice of the rats, they would select more fat and perhaps sugar than they were getting. Their physiological urge was more likely to be for calories, which, however much vitamin $\mathrm{C}$ it might contain, salad signally fails to supply.

Prof. H. Hartridge, at the same meeting, suggested that, fundamentally, the special senses - taste, smell and the others-gave the brain a quick analysis of the blood. If the salt concentration was low there was a craving for salt; if the protein concentration was low, might there not be a craving for, say, meat ? This perhaps was more speculative. These special senses also served to give warnings. On this point, Richter has an interesting experiment to quote. Some of his rats were given the opportunity of drinking their water equally and indiscriminately out of two graduated bottles. To the water in one bottle, very small but increasing concentrations of mercuric chloride were added day by day. When the amount reached 0.003 per cent, which was far too little to exert any physiological effect, the rats suddenly stopped taking the solution from the poison bottle.

Dr. D. R. Davis, of the Psychological Laboratory, Cambridge, also had some interesting comments to make. For example, rats can maintain their calorie needs on solutions of sugar, alcohol and water. When the sugar solution was exchanged for a similartasting solution of saccharine, the animals main. tained an equal calorie intake by increasing their consumption of alcohol.

Dr. Davis went on to show, however, some of the reasons why whatever biochemical powers of selection man may possess are not sufficient to enable him to dispense with his objective knowledge of nutrition. The first point is 'habituation'. Rats can get used to eating out of a pot placed in a special position and will then fail to select more nutritious food placed in an unfamiliar part of the cage. Animals get 'accustomed' to certain meal-times. Pavlov's experiments with dogs and dinner bells were mentioned here. There was also some discussion of diurnal metabolic variations; but the meeting of the Nutrition Panel seemed quite incapable of coming to any reasonable conclusions about the best meal-times for people working on awkwardly arranged shifts. The palatability of 'appropriate' food was mentioned. To a Briton, sour milk is nasty, and cream-cheese nice; putrid chicken is bad, but putrid pheasant good. Finally, there was the point that people taste with organs other than their mouth and nose. Not only can a blindfolded man not distinguish between a twopenny cigar and a three-shilling one; he rarely know's whether either is alight or not. Dr. Davis cited the example of two chocolates of identical taste and consistency but one white and the other brown. These were rated equally during blindfold tests, but when the examiners could see, they thought the white one 'fatty', 'tallowy' and generally inferior.

Dr. G. W. Scott-Blair showed how many of the ancillary sensations, such as firmness, 'liveliness' and 'body', which combine together with taste to give an individual ideas as to whether or not he likes a food, can be measured mathematically. That the mathematical functions are complicated is, apparently, no 
deterrent to the subjective influence on people assessing food. Indeed, they are prepared to compare mathematically incomparable quantities, and provided that they are young and unbiased can, apparently, consistently measure viscosity in terms of elasticity.

But whereas Dr. Scott-Blair tried to explain to a slightly mystified audience of chemists at the Nutrition Panel meeting how to measure in mathematical quantities senses, about which Prof. Hartridge as a physiologist and Dr. Davis as a psychologist had spoken, Mr. R. R. Plowman, an expert and experienced tea-taster, showed how the senses of smell, taste, sight, touch and temperature ean, in actual practice, all elegantly be combined.

Evidence which has been accumulating in the literature and much of which was summarized at this meeting of the Nutrition Panel now suggests that the special senses of taste and the rest offer, if used with proper precaution, a fruitful and new method for nutritional research. Richter quotes at least two interesting experiments with human subjects. The first concerns a $3 \frac{1}{2}$-year-old boy with undiagnosed destruction of the adrenal cortex. This child kept himself alive for more than two years by eating handfuls of salt. When he was taken under control and fed a 'proper' hospital diet he died. The second experiment is of more general application. A graph was made of the percentage of children between the ages of 5 and 14 years who liked a test sample of cod-liver oil. In general, the frequency decreased as the age increased and as the known physiological needs diminished. The precautions to be exercised when trying to carry out experiments of this nature are many and obvious. Habituation, learnt custom, suggestion, whether visual or of any other kind, are a few. Certain tastes may be exceptional to the rule, if rule it is, that animals, if given the opportunity, will choose the nutrients they need. For example, the nutritionist hitherto has been nonplussed by onions, garlic and perhaps sweetness. Furthermore, people eat food, not nutrients. Nevertheless, it has often been a safe rule when studying industrial nutrition to start from the traditional dietary pattern and try to improve on that, rather than impose a theoretical regime.

The science of nutrition has progressed a long way. It certainly has still a long way to go. Perhaps this meeting of the Nutrition Panel, where nutritionists, chemists, physiologists, psychologists and those forgotten folk who taste and choose and cannot explain, all met to talk together and partially to comprehend each other, may have served in some small way to send it off on a new, fruitful journey.

\section{THE IMPERIAL COLLEGE OF TROPICAL AGRICULTURE IN WAR-TIME}

\author{
By Prof. C. W. WARDLAW \\ University of Manchester
}

\begin{abstract}
$\mathrm{O}$ NCE established, the continuity of British institutions tends to be maintained no matter what the impact of external circumstances may be. In the gloomiest periods of the years $1940-42$ it was a feature of rife in Britain that bodies concerned with matters of eultural interest were not merely kept in
\end{abstract}

being but in some instances even acquired a new vitality. The publication of the report of the Governing Body of the Imperial College of Tropical Agriculture, Trinidad, for the year 1943, serves to remind us of yet another instance of this continuity of the national effort in the arts of peace, this time in spheres remote from the European conflict-a continuity all the more remarkable in view of the difficulties that lie in the way.

Readers may perhaps recall that the Imperial College of Tropical Agriculture was founded to provide higher instruction in tropical agriculture and in the cultivation and preparation for market of tropical produce of every kind. Practically all members of the Colonial Agricultural Service pass through the College as a first stage, or otherwise have associations with it ; thus the bonds that unite past students confer an almost unique unity and coherence to the collective personnel of this Service.

That an effort to maintain the College and its work should be made is not surprising. The developments and improvements that must be effected in agriculture in practically every corner of the Colonial Empire, both as immediate and long-range post-war aims, demand that preparations be put in hand now ; and, as we have seen, the Imperial College of Tropical Agriculture is an integral part of the system.

What is remarkable is that it has been possible to keep the establishment actively in being, to continue the recruitment and training of students, to keep the long-term experimental programmes in operation, and to turn out a not inconsiderable body of research. This is a notable achievement; it is something in which we may take a legitimate pride. But it has not been without its rigours, both for staff and students. Most of the academic staff and their families, accustomed to home leave in a temperate climate every two years, have now been continuously in the tropics for six years. Even local travel, which helps to dispel the inescapable tropical ennui, has been seriously restricted. There have been periods of food restriction, and even scarcity, more rigorous than at home ; and 'digging for victory' in the moist tropies-for that, too, has had to be done-is not quite the same pastime as in our own temperate clime.

Lack of transport provides the clue to the many difficulties. Thus Colonial Office seholars, going out to take the associateship course prior to being posted to different Colonies, have mostly arrived in small batches many months late. For example, the last of those due on October 1, 1942, arrived in the second week of April 1943 ! As in home universities, the defects of 'shortened courses have had to be borne. So, too, research work has been hampered by restrictions and delays in the arrival of apparatus and materials.

And so the tale of difficulties mounts up. The near view no doubt suggests a somewhat gloomy pieture. But there is elearly another side to it. Agrứculture is an art, and art is proverbially long. Nothing is more damaging to agrieultural progress than restriction and discontinuity in the scientifie research directed towards its improvement. In Trinidad, in spite of all set-backs (and they have been not a few), this essential continuity has been maintained. To those who have held the fort and advanced the tradition of science in its relation to agrieulture, under the stress of war, a word of recognition is due. 